\title{
What Makes Small-Scale Fishers Resilient? Lessons from the Coping Strategies under COVID-19 Outbreak Observed in Trang Province, Thailand
}

\author{
Yuki Arai ${ }^{1 *}$, Maneewan Sanlee ${ }^{2}$, Misato Uehara ${ }^{3}$, Shimpei Iwasaki ${ }^{4}$ \\ 1 Research Centre for Social Systems, Ina Campus, Shinshu University, 8304, Minamiminowa-Village, Kami- \\ ina-County, Nagano 399-4598, Japan \\ 2 Save Andaman Network Foundation, Trang Province, Thailand; maneewan19822@gmail.com \\ 3 Research Centre for Social Systems, Ina Campus, Shinshu University, 8304, Minamiminowa-Village, Kami- \\ ina-County, Nagano 399-4598, Japan; ueharam@shinshu-u.ac.jp \\ 4 Department of Environmental Science, Fukuoka Women's University, Fukuoka 813-8529, Japan; \\ iwasaki@fwu.ac.jp \\ * Correspondence: yukiarai@shinshu-u.ac.jp
}

\begin{abstract}
Researchers have reported various impacts of the COVID-19 outbreak on small-scale fishers, such as stagnating market demands, reduction of market price and income, etc. While literature have heeded to these impacts in a relatively short time frame, scant evidence exists on the changing impacts over time and on the detailed processes of how fishers have been coping with the challenges in a longer time period. Furthermore, few studies have comprehensively analysed the impacts and strategies from multiple perspectives. This study aims to explore the perceived impacts of the COVID-19 outbreak on small-scale fishing communities and to highlight the coping strategies adopted by fishers over a year since the initial outbreak, through a case study in Trang Province, Thailand. Analysis of both qualitative and quantitative data obtained through semi-structured interviews indicated that fishers wisely utilised natural, financial and social capitals at the early stages of the outbreak, while human capitals were essential for recovering from the impacts in the later stages. Our findings suggest that the adaptive capacity to flexibly change livelihood strategies are crucial, while alternative income source may not necessarily help small-scale fishers under stagnating global economy.
\end{abstract}

Keywords: small-scale fishers, resilience, Adaptive Cycle Model, Sustainable Livelihood Framework, COVID-19, coping strategy, alternative livelihood, Trang Province, Thailand

\section{Introduction}

Small-scale fishers (SSF) are generally characterised by small-sized vessels, simple or traditional fishing gears, family or local ownership, and small number of crews [1]. SSF typically operate near shorelines with relatively limited number of fish catch [2]. Part of the income source of approximately 180 million people from developing countries rely on small-scale fisheries [3]. In fact, approximately $50 \%$ of the seafood consumed in the world are caught by SSF [4].

Despite the significance of small-scale fisheries in terms of supporting the livelihoods of the poor and global seafood production, SSF are considered to be particularly vulnerable in the world. Coastal communities, where large populations depend on marine resources for their livelihoods, tend to be vulnerable to sudden shocks and longterm changes [5]. Due to overfishing, habitat loss, pollution, and climate change, coastal small-scale fishing communities are increasingly facing decreased livelihood sustainability and food insecurity [6-8]. Additionally, compared with developed countries, SSF 
tend to be more vulnerable against alterations in the global supply chains or price fluctuations [9], shocks such as natural hazards and diseases, since they have fewer means to cope with shocks [10].

Efforts to address these issues are particularly important for the SSF, calling for building resilience to adapt to changes in the social-ecological systems. While increasing literature focuses on the theoretical aspects of vulnerability, adaptability, and resilience, empirical research on how to operationalise the theories in developing countries remain limited [11]. Considering the vulnerability of the SSF, more research is necessary to understand how the global socio-economic and environmental changes may affect the SSF, and how we should plan for the rapid changes by strengthening the resilience of the SSF [7].

Since early 2020, COVID-19 has spread worldwide at an unprecedented rate. Though research remains limited, latest literature has reported various impacts of the COVID-19 outbreak on SSF. Measures and restrictions on social distancing under the pandemic has hindered SSF from venturing out for fishing [12-14]. Global industrial fishing activities were reduced by approximately $6.5 \%$ owing to the restrictions caused by COVID-19 [15]. In particular, serious impacts on fish catch and revenues have been reported in different areas around the world [16-17]. The pandemic has disrupted the global seafood market and supply chain, thereby leading to a severe reduction of market demands and market price [9,18-19,20-22]. While SSF who are dependent on export markets experienced a severe reduction of demands [13], local markets were also affected [23]. SSF suffered from income loss [4,9,14,17,24,25], unemployment [26-27] and food insecurity [28-29], as they often lack alternative source of income. Some SSF were even forced to take loans from local money lenders at high interest rates [24]. These situations also led to a loss of purchasing power [21], low consumer demands [24,30], and often severe psychological impacts and social unrests [28]. Moreover, social inequalities that caused restrictions on fishing activities, barriers to sell fish products, lack of social protection, etc. have increased vulnerability of SSF in some countries [21,31]. Furthermore, decreased capacity of monitoring and supervision [12] has led to increased pressure of Illegal, Unreported, and Unregulated (IUU) fishing within the areas used by SSF [32]. Insufficient income and decreased tourism increased the pressure on local natural resources to meet the needs for food and livelihoods [24]. Studies focusing on coping strategies under the pandemic reported that SSF helped each other through sharing of food [33-34] or peddling caught fish in communities [35], while others stressed the importance of aid from public or private actors, financial assistance, and diversification of livelihoods [35-36].

Existing literature has significantly emphasised the socio-economic impacts of the COVID-19 pandemic on small-scale fishing communities and their coping strategies at a particular time, within a relatively short time frame (i.e. mostly under six months). However, scant evidence exists on the changing impacts over time, and the detailed processes of how the SSF have been adapting to the altering socio-economic circumstances over a longer time frame (i.e. over a year). Thus, more research focusing on the long-term effects of the pandemic is necessary [26]. Additionally, most articles have studied the impacts from a particular aspect (e.g. market economy), while few studies have comprehensively analysed the impacts in terms of natural, financial, social, human, and physical capitals. Further, limited research have considered comparative analyses of different types of SSF (e.g. fishers with and without alternative income sources), exploring why some fishers are more severely affected, while others seem less affected.

To bridge these gaps, the present study aims to explore the perceived impacts of the COVID-19 outbreak and to highlight the coping strategies introduced by the SSF over one year (i.e. before, during, after the lockdown and after a year from the lockdown), through a case study in Trang Province, Thailand. The research questions of this 
study are as follows: 1) How did the SSF perceive the impacts of COVID-19 outbreak over time? 2) How have the SSF addressed the impacts caused by the COVID-19 outbreak over time?

\section{Methods}

\subsection{Analytical Framework}

This paper builds on an analytical framework that combines two different models, the "Adaptive Cycle Model (ACM)" developed by Holling and Gunderson [37] and the "Sustainable Livelihood Framework (SLF)" proposed by DFID [38]. The ACM aims at understanding resilience by unravelling the dynamics of social-ecological systems, consisting of four specific stages: the exploitation phase (r) characterised by growth and seizing of opportunities, the conservation phase $(K)$ representing stability and increasing rigidity (fore-loop), the release phase $(\Omega)$ denoting the period of decline and destruction, and the reorganisation phase $(\alpha)$ for innovation and restructuring (back-loop) [39]. The former (r to $\mathrm{K}$ ) is a slowly increasing phase with growth and accumulation, whereas the latter $(\Omega$ to $\alpha)$ is a short-term phase of destruction followed by reorganization leading to renewal [4041].

In contrast, the SLF places the poor at the centre of the development process and aims to increase the sustainability of their livelihoods. This framework focuses on livelihood asset analysis where sustainability is considered in terms of available capitals (i.e. natural, financial, social, human, and physical capitals) and an examination of the vulnerability context in which these assets exist [42]. SLF helps us identify the connections between people and the enabling environment affecting their livelihood strategies and outcomes [43]. It aims to make their lives more sustainable by (i) improving access to better education, training, technology, information, nutrition and health; (ii) creating a social environment that supports the poor, based on cooperation and collaboration; (iii) ensuring adequate access to and control over natural resources; (iv) improving access to basic infrastructure; (v) improving access to financial and economic resources; (vi) supporting a variety of survival and livelihood strategies [44].

We combined, herein, the above two frameworks, for the following two reasons. First, the SLF does not sufficiently present the time frame. Combining the SLF and ACM enables us to understand how each capital asset and livelihood strategies change over time, throughout the four stages of adaptation. Second, the ACM does not fully identify the detailed components or interactions among different factors affecting the social-ecological systems in the four stages. Our combined framework allows us to analyse what types of capital may influence the social-ecological system in each phase of adaptation, and to discuss how different capitals may affect one another over time (Figure 1). 


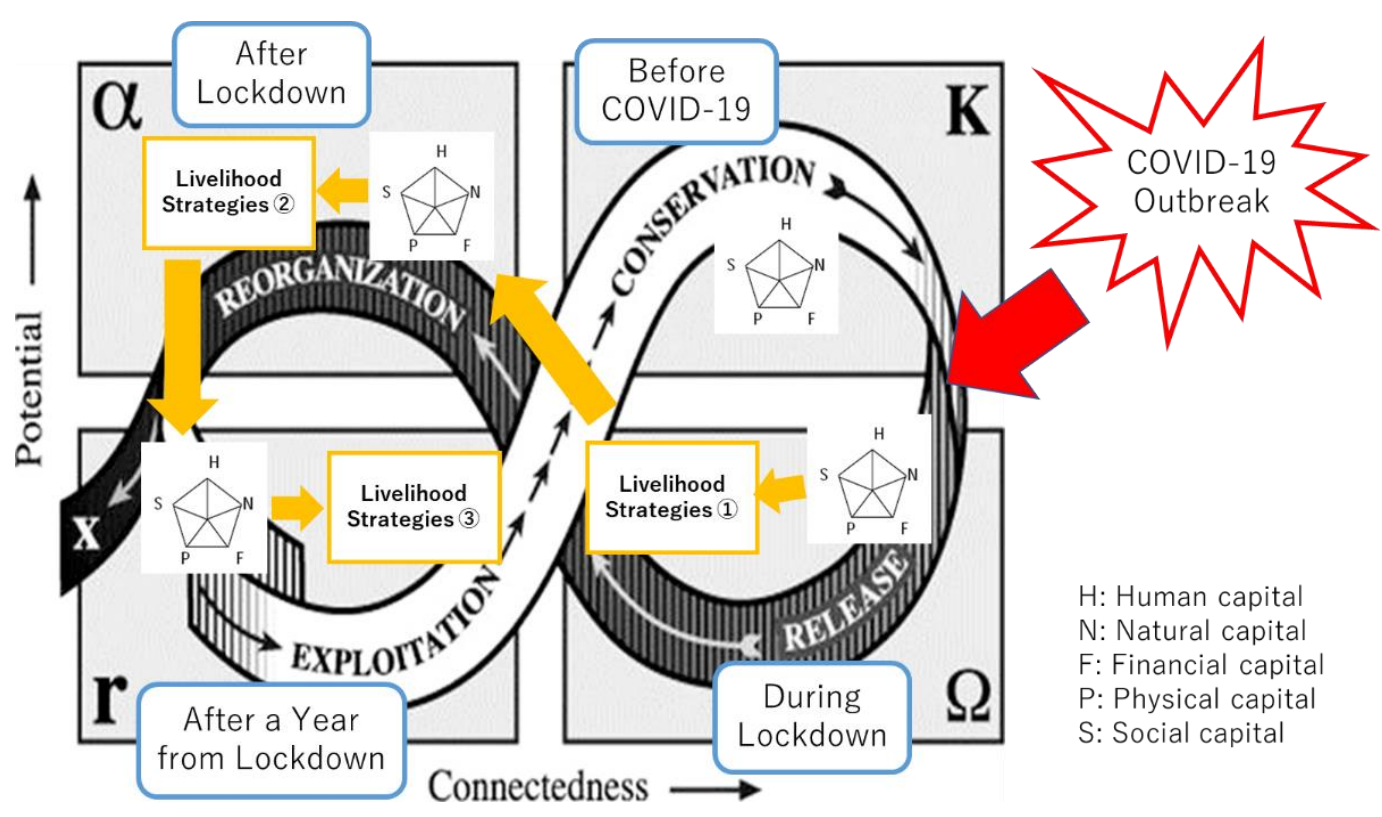

Figure 1. Analytical Framework: Adaptive Cycle Model + Sustainable Livelihood Framework. Revised from Holling and Gunderson [37] and DFID [38].

We assumed that the COVID-19 outbreak served as an external shock which influenced the social-ecological system of small-scale fishing communities to alter its status from the conservation phase $(K)$ to the release phase $(\Omega)$, because it destroyed their stable lives and led to a huge loss of resources. The conservation phase $(\mathrm{K})$ and the release phase $(\Omega)$ can be considered as the pre-COVID-19 period and the lockdown period, respectively. Since people started to restructure their livelihoods after the lockdown, this stage was identified as the reorganisation phase $(\alpha)$. Finally, the period one year after the lockdown was set as the exploitation phase (r), as this was the time when people gradually sought better livelihood opportunities.

\subsection{Data Collection and Analysis}

This study presents a case of coastal small-scale fishing communities in Trang province, Thailand. The study was conducted in May-June 2021, through an in-depth qualitative interview survey, with partial collection of quantitative data. In total, 10 target villages were selected from the coastal areas of the Trang Province, which represents the socio-economic and ecological characteristics of the region. To explore how the SSF perceived and coped with the consequences under the pandemic over time, we conducted semi-structured interviews of 38 SSF with diverse social attributes (i.e. 3-4 fishers from each village). The interview questions followed the format built on the aforementioned analytical framework, which asked the perceptions of the respondents on the impacts and coping strategies at four different stages: 1) before the COVID-19 outbreak (March 2020: $\mathrm{K})$, 2) during the initial lockdown (April-July 2020: $\Omega$ ), 3) after the initial lockdown (October 2020: $\alpha$ ), and 4) after one year from the initial lockdown (April 2021: r). In each stage, the interview questions referred to the five aspects of the impacts and coping strategies, which are natural, financial, social, human, and physical capitals (hereinafter referred to as NC, FC, SC, HC, and PC, respectively). During the interviews, we also acquired some quantitative data on natural and financial capital (i.e. daily fish catch and monthly income) for further analysis (Appendix).

The Thai co-author and her colleagues from the Save Andaman Network Foundation (a Thai NGO) met all the respondents individually and conducted the interview surveys. The surveyors received training to understand not only the objective of the study and the analytical framework, but also to learn how to effectively conduct semi-structured interviews. To avoid biased responses, the other Japanese authors did not join the interviews. 
To confirm whether the questions were understandable, pre-tests were completed by nontarget fishers before the survey. Before starting the surveys, surveyors explained the objectives of the study and how the data may be used, and obtained informed consent from all the respondents. The answers obtained from the respondents were recorded in Thai language, which was later translated into English.

Qualitative interview data obtained from the 38 respondents was analysed based on the aforementioned analytical framework, through coding and categorisation of data into themes. Additionally, the quantitative data collected during the interviews were analysed using IBM SPSS Statistics 27. To compare the income levels at different stages, we applied the Friedman test followed by the Bonferroni correction. Since we found some quantitative data missing from the survey sheets of six respondents, the statistical analyses for income and fish catch were conducted using data from 32 respondents.

The major limitation of this study is the small sample size and limited statistical representativeness; further research is necessary for generalising our outcomes. Nonetheless, we believe that conducting an in-depth case study based on the above-mentioned analytical framework would make a unique contribution, since deeper and a more comprehensive understanding of the perceptions and coping strategies of SSF over time can be obtained; which is lacking in the existing literature.

\subsection{Site Description}

Thailand is one of several major fish producing countries in the world with approximately 3.3 million individuals working in the fishing industry, of which $87 \%$ are categorised as SSF [45], producing 2.4 million tons including marine/inland capture fisheries and aquaculture [46]. Trang Province (Figure 2) is situated in the southwestern coast of Thailand, and is one of six coastal provinces facing the Andaman Sea, located along the Bay of Bengal. The coast of the Andaman Sea is blessed with rich marine ecosystems such as mangrove forests (approximately 300 million $\mathrm{m}^{2}$ ) and seagrass beds $\left(79\right.$ million $\mathrm{m}^{2}$ ), providing homes to 280 species of fish [47]. Such marine resources have been attracting a number of fishers in the area. In total, 20703 fishery establishments were confirmed in 621 fishing villages along the entire Andaman Sea coast, while 3789 fishery establishments with 8459 fishers were confirmed in 132 fishing villages in Trang province [47].

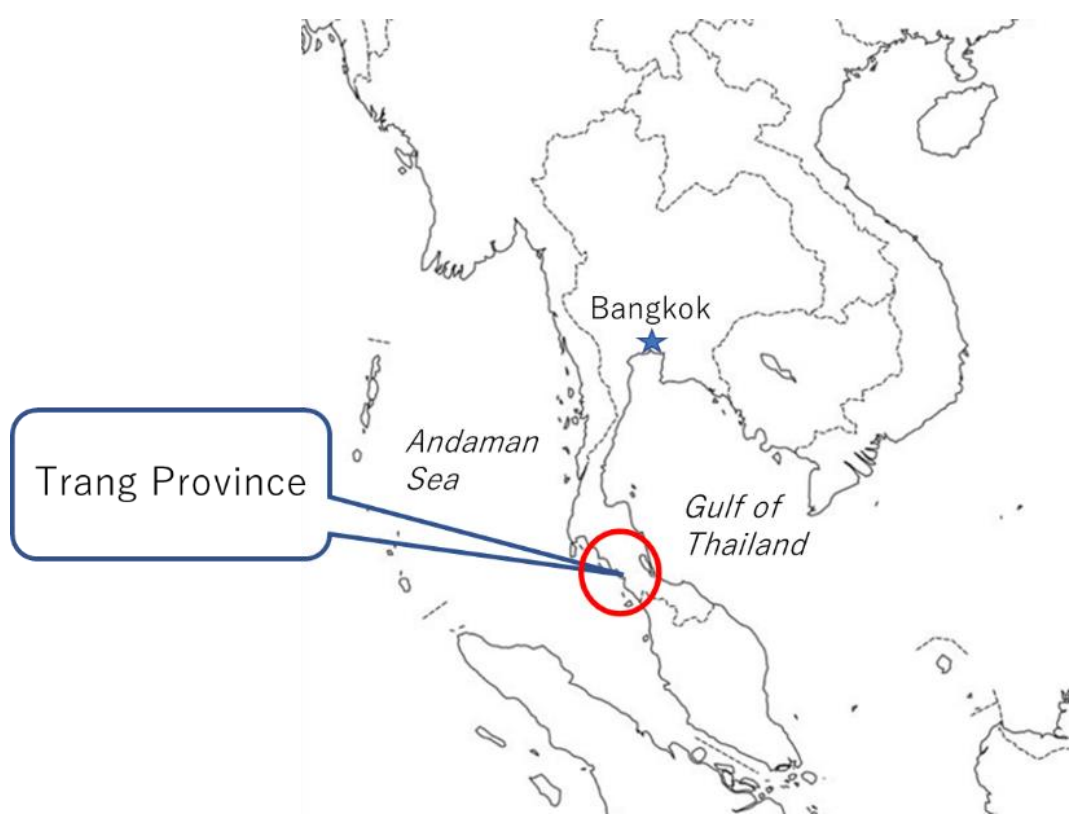

Figure 2. Location of the Study Site

The social attributes of the target fishers $(n=38)$ in 10 villages were as follows. Their ages ranged from 20s-70s; the men and women ratio was 21:17. Though there were not many differences between the roles of men/women fishers in Trang Province, women fishers tended to have less opportunities to go out for fishing than men, while they usually 
helped maintain and repair the fishing gears/equipment, or sell the products to a middleperson. The majority of the respondents $(71 \%)$ only received primary education or less and a relatively small proportion had studied in high schools $(29 \%)$, while there were no university graduates. Since the coastlines of the Trang Province is blessed with rich mangrove forests and seagrass beds [48], all the SSF in the 10 villages had access to marine resources and its ecosystem services. Out of the 32 respondents (with quantitative data), 13 fishers had an alternative income source (i.e. daily labour at oil palm/rubber plantations), from which they earned income in addition to fisheries. The other 19 fishers solely relied their income source on catching and selling fish, etc.

\section{Results}

\subsection{Before the COVID-19 Outbreak (March 2020: K)}

Before the COVID-19 outbreak, the median daily fish catch (excluding self-consumption) among all the target respondents were $7.0 \mathrm{~kg} /$ day $(\mathrm{NC})$, while the median monthly income of all the interviewed fishers reached 8500 THB (FC). Nearly $100 \%$ of the interview respondents acknowledged that they used to have strong trustworthy relationships with their family members, neighbours, colleagues, and community members before the COVID-19 outbreak (SC). 100\% of the interview respondents answered that they had no specific problems regarding their health conditions, including both physical and mental aspects (HC). As for their skills or knowledge, the vast majority $(94.7 \%)$ responded that they knew how and where to catch fish, crabs or shrimps, but did not have any other specific skills or knowledge, because most of them (71\%) only possess primary education (HC). Most of the interviewees possessed minimum gears and tools necessary for fishing, including a small-sized fishing boat, fishing nets and traps, in which the types differ depending on the targeted species of fish (PC).

\subsection{During the Lockdown (April-July 2020: $\Omega$ )}

During the lockdown period, the vast majority (95\%) of the interview respondents claimed that they had difficulties in continuing their fishing activities, owing to the closures of both domestic and international fish markets, strict government restrictions on leaving their houses, together with the fear towards virus infection; as such, data on the daily fish catch as well as income during this period was not available (NC, FC). In this period, most respondents mentioned that they continued fishing only for their own food; they did not catch fish for business purposes. Although we could not quantify the financial status during the lockdown, we presume that most target fishers had very limited income during this period. In contrast, to secure their food and to reduce expenditures to purchase other foods, such as chicken or beef, $28.9 \%$ of the interviewees increased their reliance on seafood (e.g. fish, crab, shrimp, shellfish) (NC). They managed to go fishing nearby during the unrestricted time slots. Some fishermen households consumed seafood more than twice per day. Yet, they had to spend minimum amount of money for their livings (e.g. electricity). Further, $92.1 \%$ of the respondents confessed that they had to rely on their savings, and that they eventually used up all their savings to make up for the lack of income (FC). We also confirmed that $68 \%$ of respondents received an emergency subsidy of 15000 THB from the Ministry of Finance of Thailand from April-June 2020, in order to make up for their income loss.

The majority of the respondents perceived that their social relationships were weakened compared to the situation before the outbreak (SC). The ratio of the respondents who perceived that the relationships with their family members were weakened reached $84.2 \%$. Similarly, $76.3 \%$ perceived that the relationships with the neighbours were weakened. As such, $63.2 \%$ and $60.5 \%$ perceived that the relationships with colleagues and community members were weakened, respectively.

Moreover, $32 \%$ of the respondents confessed that income reduction considerably impacted the relationships within their family. They explained that the lack of money has led 
to difficulties in sustaining their livelihoods, causing stressful conditions within their families. Further, interviewees explained that staying at home together for a long time without being able to go out also had a negative influence on their family relationships.

During lockdown, the government imposed strict regulations restricting social activities such as village meetings, cultural events, or wedding ceremonies, which deprived people of opportunities to meet and socialise. Moreover, they encountered difficulties in meeting each other owing to the added fear of virus infection. These situations created challenges in meeting with neighbours, colleagues, and community members, which appeared to be the major reason for the weakened social relationships. Moreover, interviewees explained that people who lost their income or jobs hesitated to meet with their neighbours or community members because they felt embarrassed of others knowing about their financial situations.

With time, $100 \%$ of the interviewees acknowledged sharing their fish, shellfish, shrimps or crabs with neighbours or community members, despite their fear of infection. They gradually started helping each other while taking necessary measures for risks of infection (e.g. wearing masks, keeping social distances etc.), not only to secure their own foods, but also to maintain their trustworthy relationships. In most cases, people gave some of the seafood they caught for self-consumption. Furthermore, some non-governmental groups and individual villagers collected foods (e.g. instant noodles, etc.) from relatively better-off people and redistributed them to the poor villagers.

By virtue of food sharing activities, there were certain portion of respondents who acknowledged a positive impact on their relationships, even under lockdown. Approximately $20-40 \%$ of the respondents mentioned that their relationships with neighbours, colleagues and community members were rather strengthened under the pandemic. They explained that helping each other through sharing their food or information to endure the difficult situations had strengthened their social relationships even more than before the outbreak.

The major impacts observed among the respondents regarding $\mathrm{HC}$ were the issues related with mental health. In fact, all the respondents (100\%) expressed their concerns on mental stress, particularly during the lockdown period. Because of the government regulations (e.g. prohibiting going outside, banning social events) during this period and fear of virus infection, many people had limited opportunities for leaving their houses or meeting with people other than their family members, which resulted in an increase of mental stress levels. As for physical health, among all the respondents, nobody mentioned that the respondent him/herself or their families, neighbours, or colleagues suffered or were infected by COVID-19 at the time of the interviews. Needless to say, they all gradually learned how to reduce risks of infection (e.g. wear masks, keep social distances, comply with hygiene rules, etc.). The other aspect of human capital heard from the interview respondents were related with knowledge and skills. All the interview respondents $(100 \%)$ answered that the COVID-19 outbreak did not affect their knowledge or skills during the lockdown. Regarding PC, all of the respondents (100\%) answered that the COVID-19 outbreak did not have any specific impacts on their possessions during the lockdown period.

\subsection{After the Lockdown (October 2020: $\alpha$ )-After a Year from the Lockdown (April 2021: $r$ )}

\subsubsection{Natural Capital}

After the lockdown was over $(\alpha)$ the median daily fish catch among all the target respondents was $5.0 \mathrm{~kg} /$ day, which was still smaller compared to the situation before the outbreak; $71 \%$ of the respondents perceived less markets and reduction of market price as the major reasons causing the decrease of fish catch. The interviewees mentioned that they had to catch less amounts of fish than before, because they could not sell them to the middleperson or markets at a proper price owing to the severe decline in the global and domestic market demand. Though some fishers wanted to increase their fish catch to cope with the reduction of market price, they could not do so because of their limited fishing gears and their small sized boats. Others who had better fishing gears increased their fish 
catch; however, their income was not recovered owing to low market price. They also mentioned that they had nowhere to sell the fish even if they increase the amount of catch. Thus, at least for some time after the lockdown, most of them sold their fish to limited markets such as local restaurants or local grocery stores, earning less income. After a year from the lockdown, median fish catch (excluding self-consumption) among the target fishers remained at $5.0 \mathrm{~kg} /$ day. Though respondents acknowledged that domestic markets were gradually recovering to some extent, they perceived that international markets were still inactive, and there remained difficulty in finding enough markets or middleperson as in the pre-COVID-19 period.

Our interview results highlight several coping strategies through utilisation of NC. While fishers continued to self-consume the seafood they caught, to obtain food, medicine and to reduce their daily living expenses, $60.5 \%$ of the respondents mentioned that they started growing agricultural products and medicinal plants (e.g. chili, ginger, galangal) in their home gardens for self-consumption. In April 2021, 24\% of respondents changed their target fish to the ones that had relatively higher demands and higher market price (e.g. jellyfish).

After the lockdown, $65.8 \%$ of the interview respondents noted that many villagers who used to work for tourism-related businesses (e.g. hotels, restaurants, tour guide, travel agent, etc.) lost their jobs because of the sudden decrease of tourists, and started to engage in fisheries. While local fish markets gradually started to reopen after the lockdown period, it was still difficult for tourism companies to restart their businesses; this fact encouraged tourism employees to change their occupation. Interviewees explained that because many of the parents or relatives of the unemployed people were engaging in fisheries, it was relatively easy for them to start working for fisheries by receiving necessary support or training. Interviewees mentioned that fisheries seemed to be attractive in a sense that they can at least survive by consuming fish by themselves, while other job opportunities were limited. In contrast, there were a certain portion of interview respondents $(76 \%)$ who expressed a concern about fish stocks (including crabs or shrimps) being decreased owing to increased pressure from fisheries or self-consumption, which led to a reduction of fish catch after a year from the lockdown.

\subsubsection{Financial Capital}

After the lockdown $(\alpha)$, the median monthly income of all the target fishers was 4 $500 \mathrm{THB}$, which was still $47 \%$ lower than the income level before the outbreak. Also, 77\% of the respondents indicated either less market demand or lower market price as the major reasons for the impact. They not only suffered from severe reduction of market demands, but also from the lower market price, both resulting from the stagnating global market economy. The fact that they could not sell the caught fish to the middleperson, and that the market price of fish remained to be cheap made it difficult to increase their income levels.

Our results also indicated a sharp decline of income not only among the fishers with single income source (who rely their income only on fisheries), but also fishers who had alternative income source (who have another income source in addition to fisheries) (Figure 3). The income of fishers with alternative income source decreased from $8000 \mathrm{THB}(\mathrm{K})$ to $4000 \mathrm{THB}(\alpha)$, and slightly increased to $6000 \mathrm{THB}$ in stage $\mathrm{r}$, whereas that of fishers relying on single income was reduced from 10000 THB from 6000 THB, and gradually restored to $8000 \mathrm{THB}$ in stage r. Our statistical analysis using the Friedman test with Bonferroni correction showed that the median income levels of both fishers with and without alternative income sources significantly decreased from stage $\mathrm{K}$ to $\alpha$ (single: $p<0.001 /$ alternative: $p=0.001$, while we found no significant differences between stages $\alpha$ and $\mathrm{r}$, and stages $\mathrm{K}$ and $\mathrm{r}$. Their alternative income sources were represented by daily labour at oil palm or rubber plantations, which respondents mentioned were also influenced by the restriction of production under the stagnating global economy. Although there were no significant differences, the median income levels of the fishers with single income source appeared to be higher in all three stages compared to those who had an alternative income 
source. This was probably because the fishers with better fishing gears could catch more fish, and because the single income holders had better gears among the respondents.

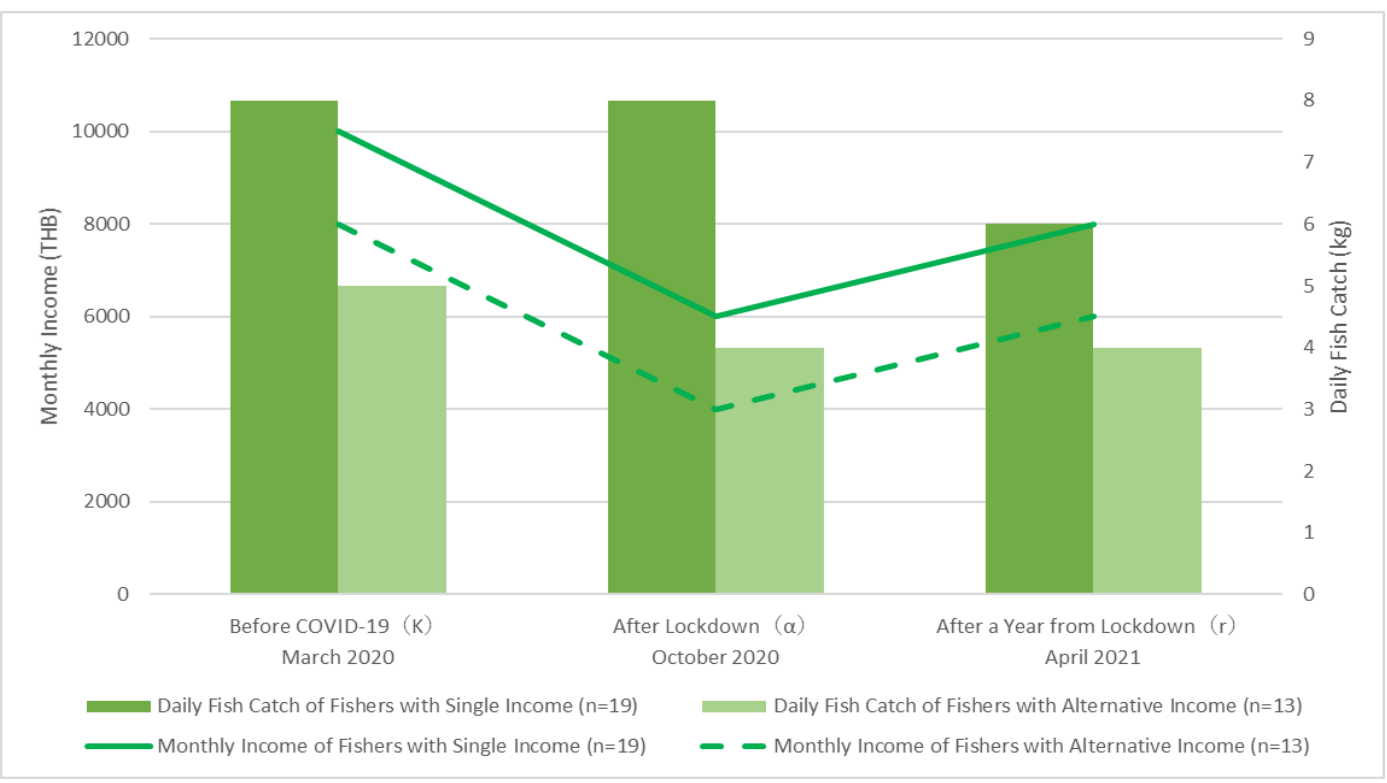

Figure 3. Monthly income (THB) and daily fish catch (kg) of fishers with single/alternative income source at three different stages before/under the COVID 19 outbreak in Trang Province, Thailand (single: $\mathrm{n}=19$ / alternative: $\mathrm{n}=13$ )

However, the expenditures of fishermen only showed a slight decrease from a median of $7000 \mathrm{THB}(\mathrm{K})$ to $6000 \mathrm{THB}(\alpha)$, equivalent to a $14.3 \%$ decrease. The respondents referred to the fact that the price of commodities increased owing to stagnating supply chain, and that they could not easily reduce their expenses in order to sustain the daily life of their family members, feeding their families, paying electricity costs, curing the sick elders, etc.

The following coping strategies to address the financial crisis were observed after the lockdown $(\alpha-r)$. As many of the respondents used up all their savings during the lockdown, $73.7 \%$ confessed going into debt. They borrowed money from relatives or family members $(23.7 \%)$, informal money lenders $(21 \%)$, banks $(18.4 \%)$, or neighbours $(10.5 \%)$ because they could not continue their livelihoods with their severely reduced income. While some people had the capacity to deal with the official procedures required to obtain a loan from a bank (e.g. providing collaterals, dealing with paper works, etc.), others did not have such capacity and had to borrow money from informal money lenders at high interest rates.

In addition, $71 \%$ of the interviewees sold fish, shrimp, shellfish, or crabs to their neighbours, colleagues and local merchants, which enabled them to earn minimum income to survive. Because the international markets were still inactive even after a year from the lockdown, they utilised their local social relationships for their survivals. Some interview respondents mentioned that selling products among community members further strengthened their social relationships, which was once weakened owing to the lockdown.

Moreover, $21 \%$ of fishers started online sales to sell products to domestic markets, including large cities such as Bangkok. Interviewees explained that their friends or family members who had the skills to sell products online (by using Facebook etc.) taught them such skills, which enabled them to sell the products to a wider group of people. In Thailand, a private delivery company provided services to deliver various products to many parts of Thailand without any cost to the fishers, which made it easier for them to sell their seafood products to the domestic consumers. Further, $11 \%$ of the fishers started to produce value-added products (e.g. crab sauce), in order to increase their income; such products were also sold through online markets. Respondents mentioned that they learned or 
taught such skills among friends with close relationships to overcome the issues of low market price and reduced income.

Through such strategies, as a whole, the income of fishermen appeared to gradually recover in the later stages; in April 2021, our results indicated that the median monthly income among the interview respondents restored to $6500 \mathrm{THB}$. Some interviewees stated that the domestic market economy was gradually reactivated, and that their efforts for increasing their income started to bear fruit. Thus, the median monthly income that used to be 8500 THB before the COVID-19 outbreak in March 2020 (K) largely decreased to 4 500 THB in October $2020(\alpha)$, while it recovered to 6500 THB in April 2021 (r), one year after the initial outbreak.

Among the respondents, two major groups with different coping strategies were observed. One comprises fishers who flexibly initiated new challenges to increase their income (e.g. sell products online, produce value-added products). The other comprises those who tended to hesitate to endure new challenges to increase their income, and mainly relied on existing natural, social, and financial capitals. The former group (i.e. "flexible fishers") succeeded in restoring their median monthly income to 9000 THB in stage r, which is equivalent to stage $\mathrm{K}$, though it was once reduced to $4500 \mathrm{THB}$ in stage $\alpha$. In contrast, the latter group (i.e. "non-flexible fishers") could only slightly restore their income from 4500 THB (stage $\alpha$ ) to 6000 THB (stage r), which was still much lower than 8000 THB in the pre-COVID stage (K) (Figure 4). The Friedman test combined with Bonferroni correction showed that the median income levels of both flexible and non-flexible fishers significantly reduced from stage $\mathrm{K}$ to $\alpha$ (flexible: $p<0.001 /$ non-flexible: $p=0.007$ ). However, the income levels of flexible fishers were significantly increased from stage $\alpha$ to $\mathrm{r}(p=0.006)$, while the income levels of non-flexible fishers exhibited no significant differences between $\alpha$ and $\mathrm{r}$. 


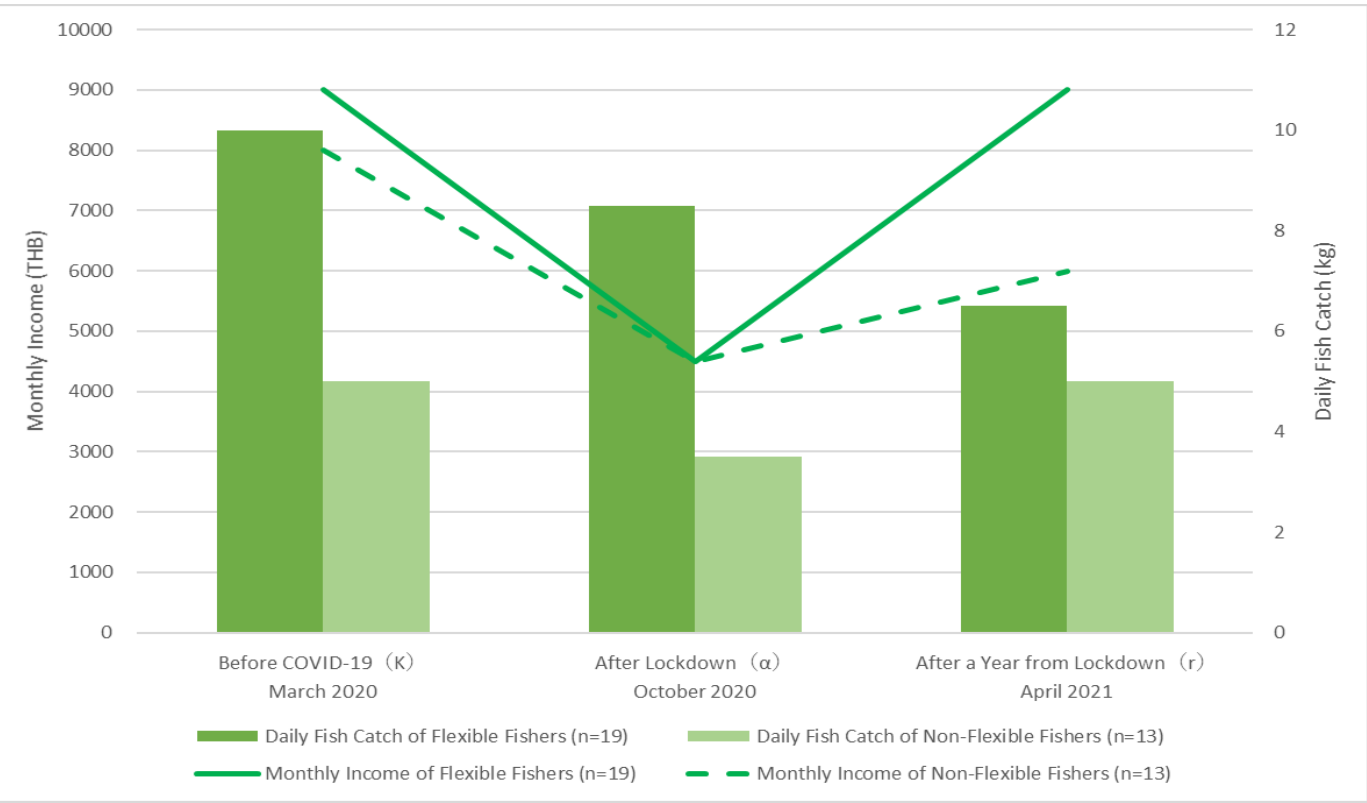

Figure 4. Monthly income (THB) and daily fish catch $(\mathrm{kg})$ of flexible/non-flexible fishers at three different stages before/under the COVID 19 outbreak in Trang Province, Thailand (flexible: $\mathrm{n}=19$ / non-flexible: $\mathrm{n}=13$ )

\subsubsection{Social Capital}

The cancellation of the lockdown appeared to be an important step forward for the social relationships of fishers, as they were allowed to go outside, move around, and meet with other people. Since the lockdown period, people learned to avoid risks of infection in their daily lives. After the lockdown, most respondents (97.4\%) mentioned that they became accustomed to wearing a mask and keeping social distances while taking walks or meeting with their colleagues or community members. In stage $r$, they were able reorganise social events such as village meetings or wedding ceremonies, though they still had to take necessary measures to prevent infection.

While they still continued to share caught seafood among neighbours or colleagues, some of them also shared their knowledge or skills. People who had the skills to sell products online taught such techniques to their family members or friends, such that the fishers can sell their fisheries products to consumers outside of their village. Furthermore, they also learned or taught each other about how to produce value-added products, which provided another opportunity to increase their income. Interviewees stressed that their social relationships strengthened compared to the situation before the pandemic, through such efforts to support each other and to overcome difficulties. Thus, though the social relationships were generally perceived to be negatively affected by majority of respondents particularly during the lockdown, it seemed to have improved at the later stage. In stage $r$, most interview respondent's relationships were perceived to be strengthened with the help of their own coping strategies.

\subsubsection{Human Capital}

As mentioned earlier, people were allowed to leave their houses, go out fishing with their colleagues, and to socialise with other community members after the lockdown. Interviewees perceived that this greatly contributed to alleviate their mental stress which they suffered from, particularly during the lockdown period.

Some of the interview respondents acknowledged that the impacts of COVID-19 provided an opportunity for them to learn new knowledge or skills, in order to overcome the issue of income loss. $21 \%$ of interviewees mentioned that they learned how to sell fisheries products online from their friends, neighbours or family members, so that they could expand their market to the entire country. To address the issues of low market price, $11 \%$ 
learned how to produce value-added products (e.g. crab sauce). One person learned and started to raise crabs in a pond, because he wanted to keep them for a while and sell them when the market price increases. Furthermore, the unemployed people who used to engage in tourism related businesses before the pandemic learned how to conduct fisheries practices, as described earlier.

\subsubsection{Physical Capital}

One person confessed that he had to sell his fishing boat and gear to make up for the income loss and to feed his family. He asked his colleagues to share the boats or gears with him to continue fishing, and was hoping to purchase a new one once he earns more income. Others also mentioned that they had to pledge their houses or accessories as collaterals when borrowing money from the banks. However, some fishers $(21 \%)$ strategically purchased a new fishing gear/boat, or repaired their gear/boat in order to increase their fish catch (mostly by taking loan), to cope with the issues of lower income caused by lower market price.

\section{Discussion}

The major impacts of the COVID-19 outbreak perceived by SSF in Trang Province during the lockdown $(\Omega)$ were as follows: 1 ) reduction of fish catch (NC); 2) decrease of income (FC); 3) weakened social relationships (SC); 4) increased mental stress (HC). The impacts associated with reduced market demands, lower market price, and decreased income match with the case study findings from many other countries (e.g. [24, 35, 36]). The major coping strategies observed during the lockdown $(\Omega)$ were as follows, also shown in Figure 5. Fishers increased self-consumption of fish, crabs, and shrimps to secure their food source and to reduce expenditures (NC1), shared caught seafood with neighbours, colleagues and community members (SC1), and used money from their savings (FC1). Moreover, to protect themselves from the virus, they learned to reduce the risks of infection (HC1). Thus, their responses seemed to strongly emphasise fulfilling the immediate needs by obtaining food and minimum amount of money required for their livings, as the top priority for the fishers was their physical survival. These findings align with the literature that natural [49], social [50], and financial capitals [51] can play an important role as safety-nets under crisis. 
Increase self-consumption of fish etc. (NC1)

Grow vegetables and medicinal plants in home gardens (NC2)

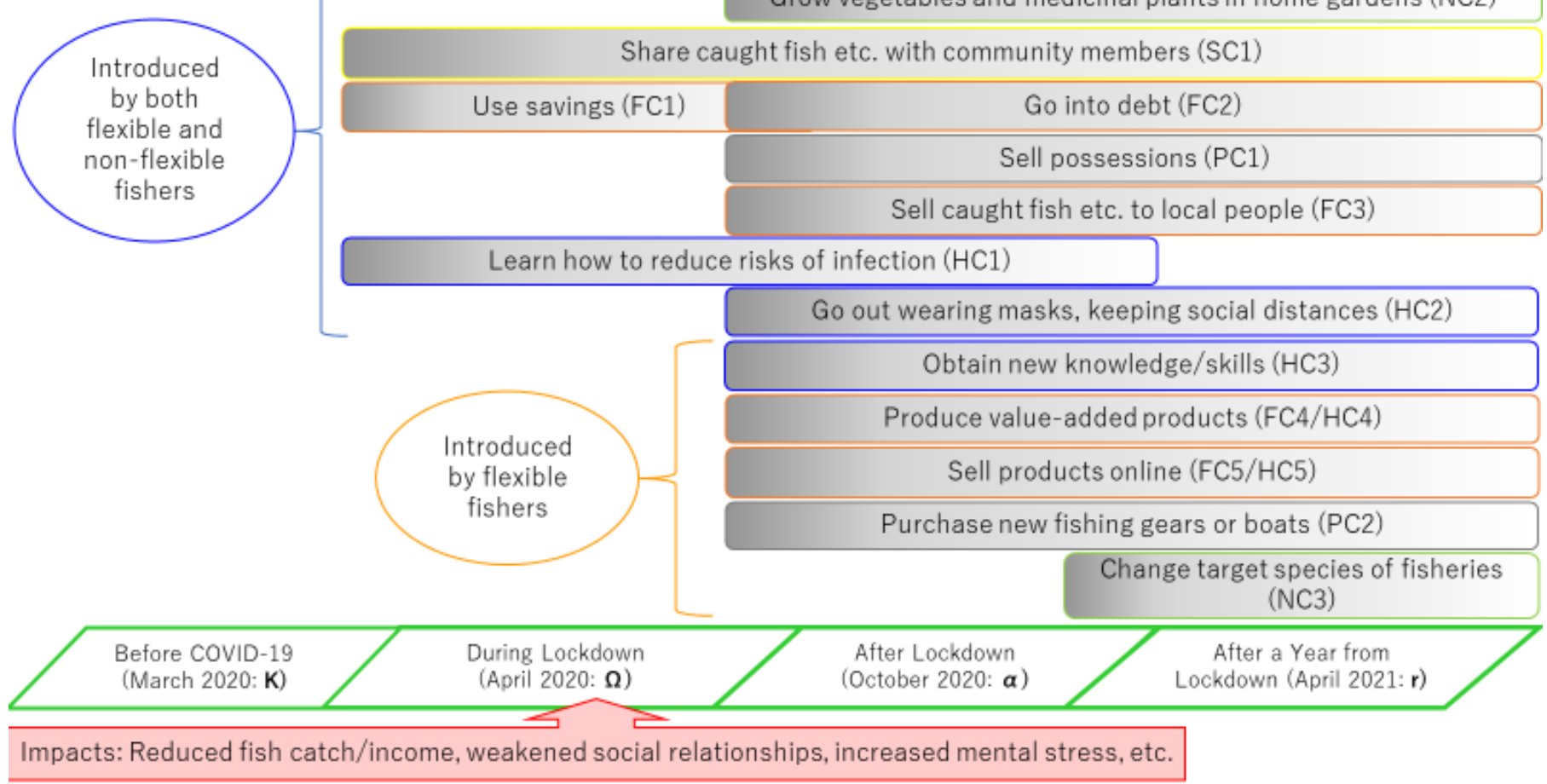

Figure 5. Coping strategies introduced by flexible/non-flexible fishers observed in different stages under the COVID-19 outbreak in Trang Province, Thailand

After the lockdown $(\alpha-r)$, as many of them used up their savings, the fishers had to go into debts, borrowing money from relatives, neighbours, informal money lenders, or banks (FC2). Another strategy frequently observed was to sell caught seafood to neighbours, colleagues, or other community members to earn minimum income (FC3). These reactions were also reported in other countries [24, 35]. Further, a certain portion of the respondents started to grow vegetables and medicinal plants in their home gardens to secure their food or medicine and to save money (NC2). One of them sold his fishing boat to make up for his income loss (PC1). Furthermore, after people were gradually allowed to leave their homes and to meet with other people, they started to socialise by wearing masks and by keeping social distances (HC2).

While these diverse coping strategies were commonly observed among the target respondents, a certain portion of target fishers appeared to have the capacity to obtain new knowledge (HC3) and flexibly initiate new challenges to improve their livelihoods. Some learned from their family, neighbours, or other community members to produce value-added products (FC4/HC4), or sell products online (FC5/HC5); thereby implementing these into their lives. Others changed target species of fisheries to the ones with higher market demand and higher price (NC3), or purchased new fishing gears/boats by taking loan to increase fish catch (PC2).

Fishers who conducted these flexible coping strategies after the lockdown until April 2021 (stage r) succeeded in restoring their income levels after the severe impact observed in April-July 2020 (stage $\Omega$ ) and October 2020 (stage $\alpha$ ). Our statistical analysis showed that the flexible fishers' income levels were significantly increased from stage $\alpha$ to $r$. In contrast, the other fishers who hesitated to make a new challenge to increase their income, and mainly relied on existing natural, social and financial capitals failed to restore their income up to the levels of the pre-COVID period. Though coping strategies such as increasing self-consumption of seafoods or growing vegetables in home gardens, using money from their savings, going into debts, sharing or selling caught fish among 
community members were widely observed among most respondents, these efforts seemed to be insufficient to restore their income levels. Since the amount of fish catch was rather decreased in April 2021, we presume that the flexible fishers were capable of increasing their income levels by improving the unit price of the products or by finding a better market, while the non-flexible fishers failed to do so. We suggest that these challenges were possible among the fishers who had higher flexibility and learning ability, which are deeply associated with their HC.

Also, we would like to highlight the role of SC in strengthening HC. As the flexible fishers utilised their social relationships with their neighbours, family members, or other community members to obtain new knowledge or skills, our findings imply that SC can help provide opportunities for fishers to access such useful knowledge and to build their adaptive capacities. Thus, we argue that HC together with SC were crucial in enhancing resilience of SSF at the later stages $(\alpha-r)$ of the adaptive cycle.

As described earlier, literature stresses the importance of diversification of livelihoods or alternative income source in enhancing resilience of SSF [5, 6, 8, 27, 49, 52, 53]. However, our findings indicated that alternative income source does not necessarily support the SSF under the COVID-19 pandemic, where the global market economy was heavily stagnating. Our statistical analyses demonstrated that the income levels of both fishers with and without alternative income source experienced a significant reduction in stage $\alpha$. Moreover, the results revealed that the fishers with alternative income source failed to significantly increase their income levels from stage $\alpha$ to r. Considering the fact that alternative income sources were represented by daily labour at oil palm or rubber plantations, we can presume that such businesses were also heavily affected by the stagnation of global market economy, just like the fisheries. Thus, our results indicate that simply obtaining alternative income sources does not necessarily help strengthen SSF's resilience under crises.

Though we need more research to generalise these findings, our results imply that diversification of livelihood alone is insufficient to strengthen resilience, particularly under global economic stagnation. Rather, we argue that "adaptive capacity" (particularly flexibility in strategies and learning ability to respond to changes), explained by Cinner et al. [54] and Cinner and Barnes [55], which enables initiating new challenges are important in enhancing resilience of SSF under crisis. As natural resources dependent communities tend to lack skills or capacity to change their occupation and find alternative livelihoods [56], building capacity of rural households to become flexible is essential for strengthening resilience [52]. Yet, we do not deny the importance of alternative income sources. As Bassett et al. [57] stressed the significance of local, domestic supply chains and networks in enhancing resilience of SSF, we suggest that their alternative income sources should not be dependent on global market, but should be incorporated within the local or domestic market economy.

\section{Conclusion}

While increasing literature has been reporting the severe impacts of the COVID-19 pandemic on SSF in a short time frame, few studies have heeded to the altering socioeconomic circumstances over time, or on how SSF addressed the impacts in a longer time frame from a comprehensive viewpoint. This study explored the perceived impacts of the COVID-19 outbreak and aimed to identify the coping strategies adopted by SSF over a year after its initial occurrence, in terms of natural, financial, social, human, and physical capitals, through a case study in Trang Province, Thailand.

Our study results indicated that the SSF have been affected by severe impacts such as reduced fish catch, loss of income, weakened social relationships, etc. Under such circumstances, SSF have focused on fulfilling their immediate needs by mainly relying on existing natural, social, and financial capitals in the early stage. In the later stage, we found 
that human capital together with social capital played a significant role in flexibly introducing new coping strategies, which helped the fishers restore their income levels. Since the target respondents with such characteristics successfully increased their income after the lockdown, we argue that human capital, namely the adaptive capacity (particularly flexibility and learning ability) is crucial in strengthening resilience of SSF under crisis like the COVID-19 pandemic.

Though literature emphasizes the importance of alternative income sources in enhancing resilience, the present study revealed that both income levels of fishers with and without alternative income source were severely affected after the COVID-19 outbreak. We suggest that providing alternative livelihood opportunities alone is insufficient, and that the income source should be based on an economic activity that is not dependent on the global market economy.

We recommend future research to compare the impacts of the pandemic between fishers with and without alternative income source in other regions or countries with different socio-economic contexts. Further, it would be also interesting to study the differences of the impacts among different types of income sources (e.g. jobs that are dependent on international markets and local markets). Finally, we expect researchers to apply our analytical framework to assess the impacts and coping strategies in other regions or countries, such that we can obtain a more comprehensive understanding for a longer time frame. Such studies may contribute in suggesting better approaches for enhancing resilience of the SSF around the globe.

\begin{abstract}
Author Contributions: This research was initiated by Y.A. and S.I. under the supervision of M.U. M.S. conducted the field interview survey, and summarised the data. The writing process was led by Y.A. in collaboration with S.I. All authors participated in the revision process. All authors have read and agreed to the published version of the manuscript.
\end{abstract}

Funding: This research was funded by the Keidanren Nature Conservation Fund.

Institutional Review Board Statement: The study was approved by the Human Ethics Committee of Shinshu University, Japan.

Informed Consent Statement: Informed consent was obtained from all the respondents involved in the study.

Data Availability Statement: All the publishable data related with this study is presented in the manuscript. However, individual data obtained through the interview survey cannot be disclosed since it includes privacy related information.

Acknowledgments: We would like to express our sincere gratitude to the Save Andaman Network Foundation and Ramsar Centre Japan for all their dedicated support for our survey.

Conflicts of Interest: The authors declare no conflicts of interest.

Appendix: Interview Guiding Questions

\title{
References
}

1. Lunn, K.E.; Dearden, P. Monitoring small-scale marine fisheries: An example from Thailand's Ko Chang archipelago. Fish. Res. 2006, 77, 60-71. DOI: 10.1016/j.fishres.2005.08.009.

2. Anuchiracheeva, S.; Demaine, H.; Shivakoti, G.P.; Ruddle, K. Systematizing local knowledge using GIS: Fisheries management in bang Saphan Bay, Thailand. Ocean \& Coastal Management 2003, 46, 1049-1068. DOI: 10.1016/j.ocecoaman.2004.01.001.

3. Eriksson, H.; Adhuri, D.S.; Adrianto, L.; Andrew, N.L.; Apriliani, T.; Daw, T.; Evans, L.; Garces, L.; Kamanyi, E.; Mwaipopo, R.; Purnomo, A.H.; Sulu, R.J.; Beare, D.J. An ecosystem approach to small-scale fisheries through participatory diagnosis in four tropical countries. Glob. Environ. Change 2016, 36, 56-66. DOI: 10.1016/i.gloenvcha.2015.11.005.

4. Knight, C.J.; Burnham, T.L.U.; Mansfield, E.J.; Crowder, L.B.; Micheli, F. COVID-19 reveals vulnerability of small-scale fisheries to global market systems. Lancet Planet. Health 2020, 4, e219. DOI: 10.1016/S2542-5196(20)30128-5.

5. Ferrol-Schulte, D.; Gorris, P.; Baitoningsih, W.; Adhuri, D.S.; Ferse, S.C.A. Coastal livelihood vulnerability to marine resource degradation: A review of the Indonesian national coastal and marine policy framework. Mar. Policy 2015, 52, 163171. DOI: 10.1016/j.marpol.2014.09.026.

6. Satumanatpan, S.; Pollnac, R. Resilience of small-scale fishers to declining fisheries in the Gulf of Thailand. Coastal Management 2020, 48, 1-22. DOI: 10.1080/08920753.2020.1689769. 
7. Kaplan-Hallam, M.; Bennett, N.J.; Satterfield, T. Catching sea cucumber fever in coastal communities: Conceptualizing the impacts of shocks versus trends on social-ecological systems. Glob. Environ. Change Hum. Policy Dimen. 2017, 45, 89-98. DOI: 10.1016/j.gloenvcha.2017.05.003.

8. Mozumder, M.M.H.; Wahab, M.A.; Sarkki, S.; Schneider, P.; Islam, M.M. Enhancing social resilience of the coastal fishing communities: A case study of Hilsa (Tenualosa Ilisha H.) fishery in Bangladesh. Sustainability 2018, 10. DOI: 10.3390/su10103501.

9. Fiorella, K.J.; Bageant, E.R.; Mojica, L.; Obuya, J.A.; Ochieng, J.; Olela, P.; Otuo, P.W.; Onyango, H.O.; Aura, C.M.; Okronipa, H. Small-scale fishing households facing COVID-19: The case of Lake Victoria, Kenya. Fish. Res. 2021, 237. DOI: 10.1016/j.fishres.2020.105856.

10. Islam, M.M.; Chuenpagdee, R. Negotiating risk and poverty in mangrove fishing communities of the Bangladesh Sundarbans. Marit. Stud. 2013, 12. DOI: 10.1186/2212-9790-12-7.

11. Schwarz, A.M.; Béné, C.; Bennett, G.; Boso, D.; Hilly, Z.; Paul, C.; Posala, R.; Sibiti, S.; Andrew, N. Vulnerability and resilience of remote rural communities to shocks and global changes: Empirical analysis from Solomon Islands. Glob. Environ. Change Hum. Policy Dimen. 2011, 21, 1128-1140. DOI: 10.1016/j.gloenvcha.2011.04.011.

12. FAO. How Is COVID-19 Affecting the Fisheries and Aquaculture Food Systems. (accessed on Dec 26, 2021); Rome, 2020. DOI: 10.4060/ca8637en.

13. Small-scale fishermen suffering significantly from COVID-19 pandemic. Seafood source. Available online: https://www.seafoodsource.com/news/supply-trade/small-scale-fishermen-suffering-significantly-from-covid-19-pandemic (accessed on December 26, 2021).

14. Giannakis, E.; Hadjioannou, L.; Jimenez, C.; Papageorgiou, M.; Karonias, A.; Petrou, A. Economic consequences of coronavirus disease (COVID-19) on fisheries in the eastern Mediterranean (Cyprus). Sustainability 2020, 12, 9406. DOI: 10.3390/su12229406.

15. Global Fisheries during COVID-19. Global Fishing Watch. Available online: https://globalfishingwatch.org/data/global-fisheries-during-covid-19 (accessed on December 26, 2021).

16. Coll, M.; Ortega-Cerdà, M.; Mascarell-Rocher, Y. Ecological and economic effects of COVID-19 in marine fisheries from the Northwestern Mediterranean Sea. Biol. Conserv. 2021, 255, 108997. DOI: 10.1016/j.biocon.2021.108997.

17. Grillo-Núñez, J.; Mendo, T.; Gozzer-Wuest, R.; Mendo, J. Impacts of COVID-19 on the value chain of the hake small scale fishery in northern Peru. Mar. Policy 2021, 134. DOI: 10.1016/j.marpol.2021.104808.

18. Korten, T. With boats stuck in harbor because of COVID-19, will fish bounce back? Smithsonian Magazine 2020, 1-7. Available online: https://www.smithsonianmag.com/science-nature/fish-stop-covid-19-180974623/accessed (accessed on on Dec 26, 2021).

19. Love, D.C.; Allison, E.H.; Asche, F.; Belton, B.; Cottrell, R.S.; Froehlich, H.E.; Gephart, J.A.; Hicks, C.C.; Little, D.C.; Nussbaumer, E.M.; Pinto da Silva, P.; Poulain, F.; Rubio, A.; Stoll, J.S.; Tlusty, M.F.; Thorne-Lyman, A.L.; Troell, M.; Zhang, W. Emerging COVID-19 impacts, responses, and lessons for building resilience in the seafood system. Glob. Food Sec. 2021, 28, 100494. DOI: 10.1016/j.gfs.2021.100494.

20. Asante, E.O.; Blankson, G.K.; Sabau, G. Building back sustainably: COVID-19 impact and adaptation in Newfoundland and Labrador fisheries. Sustainability 2021, 13, 2219. DOI: 10.3390/su13042219.

21. Mangubhai, S.; Nand, Y.; Reddy, C.; Jagadish, A. Politics of vulnerability: Impacts of COVID-19 and Cyclone Harold on Indo-Fijians engaged in small-scale fisheries. Environ. Sci. Policy 2021, 120, 195-203. DOI: 10.1016/j.envsci.2021.03.003.

22. Lopez-Ercilla, I.; Espinosa-Romero, M.J.; Fernandez Rivera-Melo, F.J.; Fulton, S.; Fernández, R.; Torre, J.; Acevedo-Rosas, A.; Hernández-Velasco, A.J.; Amador, I. The voice of Mexican small-scale fishers in times of COVID-19: Impacts, responses, and digital divide. Mar. Policy 2021, 131. DOI: 10.1016/j.marpol.2021.104606.

23. Fishing communities bear brunt of lockdown. Available online: https://business.inquirer.net/294753/fishing-communities-bear-brunt-of-lockdown (accessed on December 26, 2021).

24. Sunny, A.R.; Sazzad, S.A.; Prodhan, S.H.; Ashrafuzzaman, M.; Datta, G.C.; Sarker, A.K.; Rahman, M.; Mithun, M.H. Assessing impacts of COVID-19 on aquatic food system and small-scale fisheries in Bangladesh. Mar. Policy 2021, 126, 104422. DOI: $10.1016 /$ j.marpol.2021.104422.

25. WFP Chief Warns of "hunger Pandemic" as COVID-19 threatens food security. Devex (blog). Available online: https://www.devex.com/news/wfp-chief-warns-of-hunger-pandemic-as-covid-19-threatens-food-security-97058 (accessed on Dec 26, 2021).

26. FAO. Fishery and aquaculture country profiles: Thailand. Available online: https://www.fao.org/fishery/en/facp/tha?lang=en (accessed on Dec 26, 2021), 2019.

27. Truchet, D.M.; Buzzi, N.S.; Noceti, M.B. A 'new normality' for small-scale artisanal Fishers? The case of unregulated fisheries during the COVID-19 pandemic in the Bahia Blanca estuary (SW Atlantic Ocean). Ocean E Coastal Management $2021,206$. DOI: 10.1016/j.ocecoaman.2021.105585.

28. Russo, E.; Anelli Monti, M.; Toninato, G.; Silvestri, C.; Raffaetà, A.; Pranovi, F. Lockdown: How the COVID-19 pandemic affected the fishing activities in the Adriatic Sea (central Mediterranean Sea). Front. Mar. Sci. 2021, 8. DOI: 10.3389/fmars.2021.685808.

29. Reardon, T.; Mishra, A.; Nuthalapati, C.S.; Bellemare, M.F.; Zilberman, D. COVID-19's disruption of India's transformed food supply chains. Econ. Pol. Wkly 2020, 55, 18-22. 
30. Fisheries and Oceans Canada pulls at-sea observers from fishing boats due to coronavirus pandemic. The Narwhal. Available online: https://thenarwhal.ca/fisheries-oceans-canada-pulls-at-sea-observers-fishing-boats-coronavirus-covid-19/accessed (accessed on on Dec 26, 2021), 2020.

31. Scottish fishermen turn to food banks as Covid-19 devastates industry. The Guardian. Available online: https://www.theguardian.com/environment/2020/apr/10/scottish-fishermen-turn-to-food-banks-as-covid-19-devastates-industry (accessed on Dec 26, 2021), 2020.

32. Holling, C.S.; Gunderson, L.H. Resilience and adaptive cycles. In Panarchy: Understanding Transformations in Human and Natural Systems, Gunderson, L.H., Holling, C.S., Eds.; Island Press: Washington, DC, USA, 2002; pp. 25-62.

33. DFID. Sustainable Livelihoods; Guidance Sheets; Department for International Development: London, UK, 1999; pp. 1-10.

34. Stognief, N.; Walk, P.; Schöttker, O.; Oei, P. Economic resilience of German lignite regions in transition. Sustainability 2019, 11, 5991. DOI: $10.3390 /$ su11215991.

35. Mizutani, S.; Sasaki, T. Foundational research of education for community development to emphasize the forest-river-ocean nexus - Examination using an adaptive cycle model to evaluate resilience. Environ. Educ. 2018, 2018:2, 2-9.

36. Iwasaki, S. Disaster resilience in sustaining activities on fishers-based forest conservation initiatives: Focus on before and after the Great East Japan earthquake. J. Reg. Policy Stud. 2020, 12, 15-23.

37. Das, B.K.; Roy, A.; Som, S.; Chandra, G.; Kumari, S.; Sarkar, U.K.; Bhattacharjya, B.K.; Das, A.K.; Pandit, A. Impact of COVID-19 lockdown on small-scale fishers (SSF) engaged in floodplain wetland fisheries: Evidences from three states in India. Environ. Sci. Pollut. Res. Int. 2021. DOI: 10.1007/s11356-021-16074-9.

38. Hoque, M.S.; Bygvraa, D.A.; Pike, K.; Hasan, M.M.; Rahman, M.A.; Akter, S.; Mitchell, D.; Holliday, E. Knowledge, practice, and economic impacts of COVID-19 on small-scale coastal fishing communities in Bangladesh: Policy recommendations for improved livelihoods. Mar. Policy 2021, 131, 104647. DOI: 10.1016/j.marpol.2021.104647.

39. Sowman, M.; Sunde, J.; Pereira, T.; Snow, B.; Mbatha, P.; James, A. Unmasking governance failures: The impact of COVID19 on small-scale fishing communities in South Africa. Mar. Policy 2021, 133, 104713. DOI: 10.1016/j.marpol.2021.104713.

40. Bennett, N.J.; Finkbeiner, E.M.; Ban, N.C.; Belhabib, D.; Jupiter, S.D.; Kittinger, J.N.; Mangubhai, S.; Scholtens, J.; Gill, D.; Christie, P. The COVID-19 pandemic, small-scale fisheries and coastal fishing communities. Coastal Management 2020, 48 , 336-347. DOI: $10.1080 / 08920753.2020 .1766937$.

41. Manlosa, A.O.; Hornidge, A.K.; Schlüter, A. Aquaculture-capture fisheries nexus under Covid-19: Impacts, diversity, and social-ecological resilience. Marit. Stud. 2021, 20, 75-85. DOI: 10.1007/s40152-021-00213-6.

42. Campbell, S.J.; Jakub, R.; Valdivia, A.; Setiawan, H.; Setiawan, A.; Cox, C.; Kiyo, A.; Darman; Djafar, L.F.; Rosa, Edl; Suherfian, W.; Yuliani, A.; Kushardanto, H.; Muawanah, U.; Rukma, A.; Alimi, T.; Box, S. Immediate impact of COVID-19 across tropical small-scale fishing communities. Ocean \& Coastal Management 2021, 200. DOI: 10.1016/j.ocecoaman.2020.105485.

43. Morse, S.; McNamara, N.; Acholo, M. Sustainable Livelihood Approach: A Critical Analysis of Theory and Practice. Geographical Paper 2009, 189.

44. Harohau, D.; Blythe, J.; Sheaves, M.; Diedrich, A. Limits of tilapia aquaculture for rural livelihoods in Solomon Islands. Sustainability 2020, 12, 4592. DOI: 10.3390/su12114592.

45. JICA. A book to understand the recent trends of international development assistance. (in Japanese). Available online: https://openjicareport.jica.go.jp/360/360/360_000_11743572.html (accessed on Jan 3, 2022), 2003.

46. The World Bank. The Hidden Harvest. The Global Contribution of Capture Fisheries, 2012. Available online: https://www.researchgate.net/publication/277664581_World Bank 2012 The Hidden Harvest The global_contribution of capture fisheries. (accessed on December 26, 2021).

47. Panjarat, S. Sustainable Fisheries in the Andaman Sea Coast of Thailand. Division for Ocean Affairs and the Law of the Sea Office of Legal Affairs; The United Nations: New York, 2008.

48. Chansang, H.; Poovachiranon, S. The distribution and species composition of seagrass beds along the Andaman Sea coast of Thailand. Phuket Mar. Biol. Cent. Res. Bull. 1994, 59, 43-52.

49. Coulthard, S. Adapting to environmental change in artisanal fisheries - Insights from a South Indian Lagoon. Glob. Environ. Change Hum. Policy Dimen. 2008, 18, 479-489. DOI: 10.1016/j.gloenvcha.2008.04.003.

50. Salik, K.M.; Jahangir, S.; Zahdi, WuZ.; Hasson, Su. Climate change vulnerability and adaptation options for the coastal communities of Pakistan. Ocean \& Coastal Management 2015, 112, 61-73. DOI: $10.1016 /$ j.ocecoaman.2015.05.006.

51. Pomeroy, R.; Arango, C.; Lomboy, C.G.; Box, S. Financial inclusion to build economic resilience in small-scale fisheries. Mar. Policy 2020, 118. DOI: 10.1016/j.marpol.2020.103982.

52. Marschke, M.J.; Berkes, F. Exploring strategies that build livelihood resilience: A case from Cambodia. Ecol. Soc. $2006,11$. DOI: $10.5751 /$ ES-01730-110142.

53. Jara, H.J.; Tam, J.; Reguero, B.G.; Ganoza, F.; Castillo, G.; Romero, C.Y.; Gévaudan, M.; Sánchez, A.A. Current and future socio-ecological vulnerability and adaptation of artisanal fisheries communities in Peru, the case of the Huaura province. Mar. Policy 2020, 119. DOI: 10.1016/j.marpol.2020.104003.

54. Sharifuzzaman, S.M.; Hossain, M.S.; Chowdhury, S.R.; Sarker, S.; Chowdhury, M.S.N.; Chowdhury, M.Z.R. Elements of fishing community resilience to climate change in the coastal zone of Bangladesh. J. Coast. Conserv. 2018, 22, 1167-1176. DOI: 10.1007/s11852-018-0626-9.

55. Cinner, J.E.; Adger, W.N.; Allison, E.H.; Barnes, M.L.; Brown, K.; Cohen, P.J.; Gelcich, S.; Hicks, C.C.; Hughes, T.P.; Lau, J.; Marshall, N.A.; Morrison, T.H. Building adaptive capacity to climate change in tropical coastal communities. Nature. Clim. Change 2018, 8, 117-123. DOI: 10.1038/s41558-017-0065-x. 
56. Cinner, J.E.; Barnes, M.L. Social dimensions of resilience in social-ecological systems. One Earth 2019, 1, 51-56. DOI: 10.1016/j.oneear.2019.08.003.

57. Bassett, H.R.; Lau, J.; Giordano, C.; Suri, S.K.; Advani, S.; Sharan, S. Preliminary lessons from COVID-19 disruptions of small-scale fishery supply chains. World Dev. 2021, 143. DOI: $\underline{10.1016 / j . w o r l d d e v .2021 .105473}$. 